
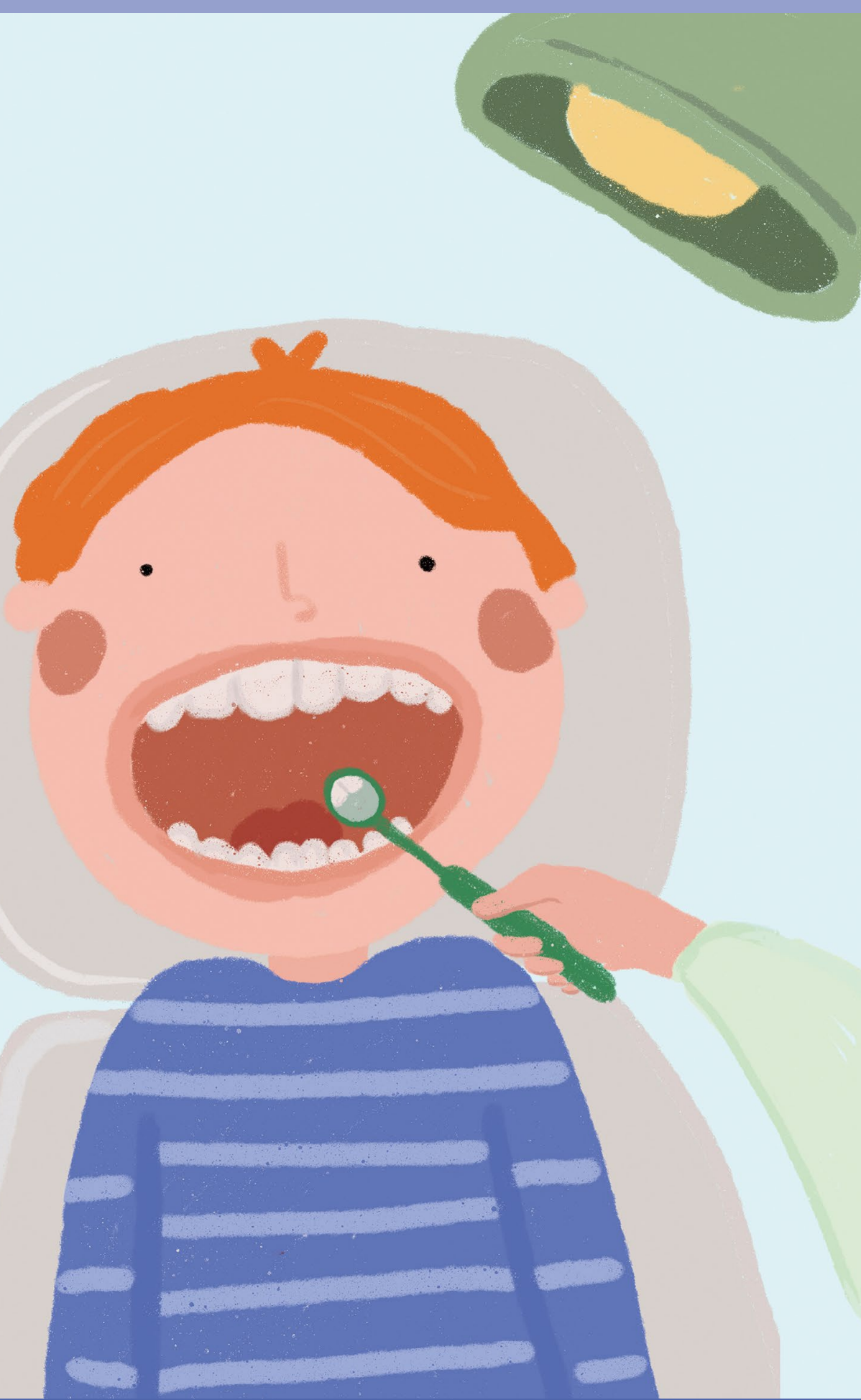

\section{FIVE TIPS ON HOW TO SPEAK 'CHILDRENESE'}

\author{
By Nicole Hasoon
}

G oing into paediatric clinics can be daunting. Younger children not only find it difficult to tell us how they feel, but also to understand what we are trying to tell them. ${ }^{1}$ Learning how to interact with children is like learning a whole new language: you use different words and need to talk in a whole new style. Here are five basic tips on how to speak 'Childrenese'.

\section{Talking to the child directly}

The first tip is to remember to talk directly to the child. Introduce yourself and use their name to begin developing a relationship. Whilst it is necessary to get valid consent for the treatment plan from the guardian present, we often forget to let the child know what's going on. It's the fear of the unknown which is scary. By talking to the child, getting to know them, and telling them what you're doing, you will gain their trust and they will be more likely to co-operate! You can also give them a degree of control by creating a mutually agreed 'stop signal'. Getting the parent involved as support can also be helpful assistance if you need it.

\section{How to talk}

Get down to their level. Kneel down so you seem less 'big and threatening'. Depending on their age and level of previous experience at the dentist, we can seem quite intimidating as we talk to them in full PPE (during COVID19 times) and in the new noisy environment. To counteract this, we must talk with a soft tone and a caring smile. We should speak loudly, slowly, and clearly to give them the best chance of understanding. It is also helpful to make direct eye contact, so they know when we are talking to them.

\section{New vocab}

One of the most important tips to remember when dealing with kids is to choose the right words. Learn a list of words and phrases that they will definitely be familiar with. Jargon such as 'anaesthetic' and 'suction' will frighten them. Fear-inducing words like 'needle' and 'drill' should also be avoided. Using friendly age-specific words will help put the child at ease. It's handy to listen out for substitute words and create your own database of 'Childrenese' vocabulary. See Table 1 for examples I have picked up or made along the way. 


\section{Work effectively}

Working with children is not the time to be faffing around. If the child is being compliant and happy with their mouth open, you should be doing dentistry. Children are unpredictable and can flip the switch at any moment. Once they've decided they've had enough, that'll be it for the day. Before going on to the paediatric clinic, make sure you are clear of the order of steps of any procedures to be undertaken that day. Make sure you have all the equipment and materials set up and ready to use. Teamwork is vital in paediatrics. Your nurse should help talk to the child and, together, you should perform four-handed dentistry.

\section{'Working with children is not the time to be faffing around. If the child is being compliant and happy with their mouth open, you should be doing dentistry'}

\section{Behaviour management \\ techniques}

One widely successful technique is the 'tellshow-do'. This involves describing what is about to happen, demonstrating the action outside of the mouth and letting the child see the involved materials, before proceeding to carry it out. This sequence helps reduce 'anticipatory anxiety' as they can mentally prepare. A commonly used technique we tend to naturally use without being taught is positive reinforcement. Encouragement through repeated praise gives the child a sense of achievement. This action helps subconsciously shape the child's behaviour as they begin to understand what is expected of

\begin{tabular}{|c|c|}
\hline Childrenese terms & Dental word \\
\hline Tooth paint & Fissure sealant \\
\hline Hoover & Suction \\
\hline Silver star & Amalgam \\
\hline Acid etch & Tooth shampoo \\
\hline Glue & Dentine bond \\
\hline Buzzy bee & Slow handpiece \\
\hline Whizzy brush & Air rotor \\
\hline Rubber raincoat & Rubber dam \\
\hline Clip/ring & Rubber dam clip \\
\hline Sleepy juice & Local anaesthetic \\
\hline Fuzzy & Numb \\
\hline Putting your teeth off to sleep & Giving a local anaesthetic \\
\hline Magic wind & Inhalation sedation \\
\hline
\end{tabular}

them. Distraction can also be a very effective method. It can be done through whatever you have access to from television and music to simply asking the child questions. Through subtly shifting the focus away from the dental procedure, you may be able to save yourself a lot of time and effort.

\section{Conclusion}

These five basic tips provide a foundation for managing children. As you go through your own clinics, you will develop a style that works for you. Most dental students will end up in general practice where we will see families of children everyday- and sometimes all at once. Some children will be easier than others but there will undoubtedly be more difficult cases, so it is important we develop our own techniques now so we can successfully handle them in the future.

\section{Reference}

1. Gupta A, Marya C M, Bhatia H P and Dahiya $\mathrm{V}$. Behaviour management of an anxious child. Stomatolog 2014; 16: 3-6.

https://doi.org/10.1038/s41406-021-0273-8 